\title{
Tradução e imitação: correspondências formal e funcional para o hexâmetro e o dístico elegíaco greco-latinos em língua portuguesa nos séculos XVI e XVII
}

\author{
Translation and Imitation: Formal and Functional \\ Correspondences For the Hexameter and the Greco-Latin \\ Elegiac Couplet in the Portuguese Language in the 16th \\ and 17th Centuries
}

\author{
Willamy Fernandes Gonçalves \\ Universidade de São Paulo (USP), São Paulo, São Paulo / Brasil \\ willamyfernandes@gmail.com
}

Resumo: O presente artigo examina como, a partir das primeiras influências do humanismo italiano, os autores portugueses traduziram e imitaram os gêneros antigos. Examina especificamente o modo como esses autores buscaram correspondentes métricos e estróficos portugueses para reproduzir aspectos formais ou funcionais dos metros antigos. Tendo como base os conceitos de correspondência funcional e formal apresentados por Britto (2016), compara os metros vernáculos aos antigos quanto à forma e aos contextos em que são utilizados. Conclui que o uso de correspondências funcionais foi predominante nesse período, apontando, entretanto, para o caráter relativo dessas duas formas de correspondência e para a dinâmica que subjaz ao processo de apropriação de formas estrangeiras.

Palavras-chave: correspondências métricas; hexâmetro; dístico elegíaco; metros portugueses; séculos XVI e XVII.

Abstract: This paper examines how, from the first influences of the Italian humanism,
Portuguese authors translated and imitated the ancient genres. It examines specifically
the way in which these authors used Portuguese metrical and strophic correspondents
to reproduce formal or functional aspects of the ancient meters. Based on the concepts
of functional and formal correspondence presented by Britto (2016), it compares the
vernacular meters to the ancient concerning both the form and the contexts in which they 
are used. It concludes that the use of functional correspondences was predominant in this period, pointing, however, to the relative character of these two forms of correspondence and to the dynamics that underlies the process of appropriation of foreign forms.

Keywords: metric correspondences; hexameter; elegiac couple; Portuguese meters; sixteenth and seventeenth centuries.

\section{Considerações iniciais}

Comparando o número de traduções de literatura latina publicadas no Brasil em cada década desde a fundação da primeira imprensa do país, em 1808, até 2014, Fernandes (2017, p. 106) mostra que após décadas de números relativamente constantes, há um aumento brusco no número de traduções publicadas: as 50 traduções publicadas na década de 1990 são mais que o dobro das 24 publicadas na década de 1980, que, não obstante, representava, até então, o período com maior número de publicações de traduções de literatura latina no Brasil. Fernandes, assim como já fizera Duarte (2016) antes dela, atribui esse aumento repentino no número de traduções publicadas à forte presença da tradução nos cursos de pósgraduação em letras clássicas.

Porém, não são apenas traduções inéditas que contribuem para esse número, mas também significativas republicações dos séculos precedentes, ${ }^{1}$ algumas vezes até em conjunto com edições de novas traduções, sugerindo-se uma comparação entre velhas e novas. ${ }^{2}$ Esse

\footnotetext{
${ }^{1}$ A tradução de trechos das Metamorfoses por Bocage, por exemplo, tem pelo menos quatro edições recentes (OVÍDIO, 2000, 2003, 2007, 2016); a tradução da Arte poética de Horácio por Cândido Lusitano também voltou a circular nas livrarias (HORÁCIO, 2017?), as traduções de Odorico Mendes voltaram a circular em edições ricamente comentadas ou em edições populares: do latim, as Bucólicas e a Eneida (VIRGÍLIO, 2004, 2005a, 2005b, 2008a, 2008b); do grego, a Ilíada e a Odisseia (HOMERO, 2000, 2002, 2003, 2010). Também a tradução da Eneida por Barreto Feio (VIRGÍLIO, 2004). ${ }^{2}$ A edição do canto I das Geórgicas de Virgílio (2013), além de apresentar a tradução inédita de Matheus Trevizam, em prosa, traz também a tradução oitocentista de António Feliciano de Castilho. Já a edição das Bucólicas (VIRGíliO, 2005a) apresenta tanto a nova tradução, de Raimundo Carvalho, quanto a tradução oitocentista de Odorico Mendes. A edição da Arte de amar (OVÍDIO, 1992), além da tradução poética dos portugueses Natália Correia e David Mourão-Ferreira, traz como apêndice "a tradução erudita de Antônio Feliciano de Castilho".
} 
segundo grupo mostra que não são apenas textos latinos inéditos em português que são publicados, mas também inúmeras retraduções, que são motivadas não por mera atualização linguística, mas por terem concepções tradutórias distintas, conforme testemunham as diversas traduções contemporâneas de textos de Virgílio, Propércio e Ovídio em trabalhos acadêmicos, por exemplo. Também não é incomum que velhas soluções tradutórias sejam resgatadas e reaplicadas em outros poemas latinos. ${ }^{3}$

Desse modo, parece lícito afirmar que um dos aspectos característicos do atual momento da história da tradução dos clássicos no Brasil é o que se pode chamar de "pancronia", ou seja: convivem a um só tempo todas as fases dessa história, seja pelas republicações de velhas traduções, seja pela retomada de velhas soluções de tradução poética por novos tradutores.

Oliva Neto (2016a) aponta que a retomada de velhas soluções por vezes ocorre de forma relativamente inconsciente, seja por não ser possível identificar a fonte daquela proposta, seja por retomá-la, tendo como base uma leitura não exata dessas soluções anteriores, de modo que sua retomada acaba ficando aquém do seu potencial original. Frequentemente, a solução buscada aos tradutores anteriores diz respeito à métrica. Isso se deve em grande parte à crítica que se têm feito desde finais do séc. XX à insuficiência das traduções filológicas, que abrem mão dos aspectos formais dos textos antigos para poder expor com maior fidelidade seus aspectos semânticos. Na esteira dos desenvolvimentos da teoria da tradução nas décadas finais do séc. XX, argumenta-se que sendo poético o texto traduzido, sua tradução deve ser igualmente apresentada como poesia. Britto apresenta de forma bastante sucinta o que parece ser o objetivo de grande parte das traduções poéticas publicadas recentemente no Brasil:

${ }^{3}$ Thamos (2011) retoma o estilo de Bocage para sua tradução do canto I da Eneida, Gonçalves et alii (2011) aplicam a solução de Nunes a um trecho das Metamorfoses, assim como Souza (2016) numa tradução do livro I dos Amores de Ovídio e Oliva Neto (2016a, 2016b) retoma a solução de que Péricles Eugênio da Silva Ramos (1964) se utilizara em sua tradução da elegia II, 27 de Propércio e aplica sua solução a outras elegias de Propércio e Sulpícia. 
A tradução de um poema não é, em nenhum sentido estrito do termo, equivalente ao original; o máximo que se pode exigir de um poema traduzido é que ele capte algumas das características reconhecidas como importantes do poema original, e que seja lido como um poema na língua-meta. (BRITTO, 2006, p. 56)

Um dos aspectos mais evidentes que marcam a diferença entre prosa e verso e que, portanto, tem sido buscado por muitos tradutores é a metrificação. Nesse aspecto, o panorama atual é variado, sendo comum, inclusive, que um mesmo tradutor, num mesmo trabalho, apresente soluções métricas diversas para a tradução de um mesmo texto. ${ }^{4}$ Essa variedade de propostas tem como um dos seus motivos uma diferença fundamental entre as línguas antigas e o português: enquanto a prosódia grega e latina é morônica (suas sílabas podem ser longas ou breves), o português tem uma prosódia acentual (suas sílabas podem ser tônicas ou átonas). Na poesia grega e latina, há versos silábicos, tais como o senário iâmbico (que contém sempre doze sílabas) e o hendecassílabo falécio, no entanto seus dois versos mais célebres, o hexâmetro e o pentâmetro, são versos moraicos, o que os torna incomensuráveis com os versos portugueses. Na prática, isso dificulta o estabelecimento de uma equivalência formal entre os versos antigos (cuja regularidade advém da duração, não importando quantas sílabas os formem, contanto que a duração permaneça regular $^{5}$ ) e os metros das línguas neolatinas, cuja regularidade reside justamente na quantidade de sílabas poéticas, conforme revela a própria nomenclatura utilizada para designar os diferentes metros.

De modo geral, a diversidade de soluções métricas que têm sido apresentadas para superar, ainda que em caráter inevitavelmente parcial, essa incomensurabilidade pode ser dividida em dois tipos: de um lado,

\footnotetext{
${ }^{4}$ Cf. Vieira (2008), Flores (2011) e Souza (2016).

${ }^{5} \mathrm{O}$ número de sílabas oferece justamente um espaço de liberdade e elemento de variação dentro da regularidade e, no hexâmetro, pode variar de treze sílabas (no caso de todos os pés, com exceção do quinto, serem espondeus) a dezessete (no caso de todos os pés serem dáctilos).
} 
aquelas que se justificam pela busca de uma correspondência funcional entre o verso da tradução e o original; do outro lado, aquelas que se justificam pela busca de uma correspondência formal. É Britto (2006) que apresenta essas duas formas distintas de tentar resgatar características importantes do original em tradução poética. Não por acaso, o elemento a partir do qual Britto escolhe exemplificar essa oposição é o verso. $\mathrm{O}$ autor, tradutor de literatura inglesa, toma como exemplo poemas de Emily Dickinson. De forma bastante resumida, Britto mostra que grande parte desses poemas usa uma estrofe de quatro versos, alternando versos de seis sílabas com versos de oito sílabas. Se o tradutor buscar uma correspondência formal em português, ele terá que recriar essa mesma sequência de hexassílabos e octossílabos. Porém, tais metros são bem pouco frequentes na tradição poética em língua portuguesa e Britto nota que, ao contrário, a estrofe usada por Dickinson tem caráter popular no sistema literário inglês. Se o tradutor quiser criar um poema em português funcionalmente correspondente ao original, ele terá que responder à pergunta "que metro ou estrofe exerce em português aproximadamente a mesma função que essa estrofe 6-8-6-8 exerce no sistema literário inglês?". Para Britto, seria a quadra de versos de sete sílabas, a redondilha maior, de modo que se perde inclusive a alternância entre versos maiores e versos menores presente no original. Chega-se, portanto, a resultados bastante diferentes conforme o critério de correspondência utilizado.

Naturalmente, os critérios que Britto aplica à estrofe de Emily Dickinson podem ser aplicados também aos dois mais célebres metros fixos da literatura clássica: o hexâmetro e o dístico elegíaco. $\mathrm{O}$ objetivo do presente trabalho não será oferecer nenhuma nova solução baseada nesses critérios, mas apenas avaliar a presença dessas duas formas de correspondência ao longo da história da tradução dos clássicos para a língua portuguesa. Enquanto para a busca de uma correspondência formal deve-se analisar apenas as características materiais do próprio texto a ser traduzido, para a busca de uma correspondência funcional, é preciso recorrer a comparações mais amplas em que se incluem os contextos literários da cultura de chegada e da cultura em que se originou o texto a ser traduzido. Por essa razão, apesar de o foco deste artigo ser a história 
da tradução da literatura clássica para a língua portuguesa, referências paralelas à tradição literária em língua portuguesa são inevitáveis. Essas referências se restringem, entretanto, a aspectos relacionados à imitação de gêneros clássicos, mais especificamente, à métrica e às estrofes adotadas pelos autores portugueses para esse fim.

Os critérios de correspondência funcional e formal podem ser aplicados a outras características importantes em textos poéticos (a ordem das palavras, por exemplo), porém, é sensível que no panorama brasileiro atual a preocupação com a métrica tem precedência sobre a questão sintática: a versificação e a fidelidade a efeitos poéticos conseguidos pela ordenação das palavras são objetivos cuja conciliação é difícil, uma vez que a liberdade com a ordem das palavras facilita o trabalho de manter o padrão métrico. A preocupação com a métrica é, além disso, uma marca que identifica a tendência brasileira na busca de oferecer traduções poéticas dos textos clássicos, opondo-a à tendência portuguesa contemporânea: enquanto no Brasil experimenta-se uma variedade de metros fixos, em Portugal é predominante o uso de versos livres. ${ }^{6}$

A oposição apresentada por Britto (2016) tem a vantagem adicional de estar correlacionada a todo um elenco de oposições centrais nas recentes discussões de teoria da tradução: as oposições entre equivalência dinâmica e equivalência formal (Nida), entre domesticação e estrangeirização (Venuti), entre tradução etnocêntrica e tradução ética (Berman), entre ciblistes e sourciers ou entre tradutores ciosos pela

\footnotetext{
${ }^{6} \mathrm{~A}$ tendência portuguesa tem certa motivação didática e é abertamente preocupada com o objetivo de divulgação dos clássicos junto ao leitor comum. Isso reflete-se, por exemplo, no fato de suas edições serem monolíngues enquanto as traduções brasileiras são publicadas em edições quase sempre bilíngues. Participam dessa tendência os tradutores Frederico Lourenço, com a Ilíada e a Odisseia de Homero (2014a, 2014b); Luís Manuel Gaspar Cerqueira, com Da natureza das coisas, de Lucrécio (2015) e Eneida de Virgílio (2011), esta última, uma tradução coletiva feita por professores da Faculdade de Letras de Lisboa. Incluem-se nesse grupo, também, Paulo Farmhouse Alberto com Metamorfoses, de Ovídio (2014), Carlos Ascenso André com Amores (2006), Arte de amar (2008), Remédios contra o amor (2015) e Heroides (2015), de Ovídio e Poemas, de Tibulo (2015) e Domingos Lucas Dias com as Metamorfoses, de Ovídio (2017b).
} 
legibilidade do texto e pelo aspecto gramatical da língua de chegada e os chamados neoliteralistas. Ressalvadas as particularidades de cada par de conceitos, o primeiro elemento de cada uma dessas oposições parece estar paradigmaticamente correlacionado ao primeiro elemento de cada uma das outras oposições, ocorrendo o mesmo com o conjunto dos segundos elementos.

A base deste trabalho é o mapeamento das diferentes formas poéticas de se traduzir o hexâmetro e o dístico elegíaco em português. A grosso modo, observa-se um gradativo aumento na extensão dos versos, desde as redondilhas do séc. XV e início do XVI até o verso de 16 sílabas cunhado por Carlos Alberto Nunes no séc. XX, de modo que há uma coincidência entre a ordem crescente dos versos e a ordem cronológica de sua adoção sistemática para traduzir ou imitar o hexâmetro e o dístico elegíaco. Uma vez que o estudo de todo esse quadro extrapolaria em muito as dimensões de um artigo, optamos por dividi-lo em três partes, abarcando no primeiro período aqui estudado os séculos XVI e XVII: trata-se de um momento axial na história da literatura portuguesa, um momento de ruptura em que gêneros que se encontravam em estado incipiente em suas sementes autóctones, tais como teatro e épica, têm seu desenvolvimento abruptamente interrompido pelo impacto de uma tradição externa já desenvolvida, a italiana, que passa a ser imitada, repetindo algo similar ao que ocorreu no Lácio no séc. III a. C. com o influxo da cultura helenística. ${ }^{7}$

Todo o período aqui abarcado caracteriza-se pela influência direta da cultura italiana, origem do humanismo e do barroco. Essa ascendência italiana sobre a cultura portuguesa cederá lugar à influência francesa no século XVIII. Do ponto de vista formal, é marcante a presença da rima que, no que diz respeito às traduções, representa clara acomodação dos textos de partida ao sistema literário de chegada, facilitando sua recepção e sua integração ao sistema literário local. Também motivou tal recorte a presença de um hiato barroco, caracterizado por uma queda no interesse pelos clássicos e que separa o classicismo quinhentista do

\footnotetext{
${ }^{7}$ Sobre as sementes de um primitivo teatro português nas cantigas d'amigo, veja-se Cohen (2011).
} 
neoclassicismo setecentista que, por sua vez, representa um segundo impulso classicizante na história da literatura portuguesa. Nesse novo impulso, que deverá ser tratado num outro artigo, é característica a negação da rima e consequente desmonte das estrofes italianas, como a terza e a oitava rima: essa mudança será justificada como uma forma de imitação mais precisa ou, para usar os termos de Britto (2006), como um passo rumo a uma correspondência formal, uma vez que a rima não era elemento importante da poesia clássica greco-latina.

\section{Correspondências métricas na tradução e na imitação dos gêneros clássicos}

No Cancioneiro geral (1516) compilado por Garcia de Resende aparecem as mais antigas traduções poéticas de literatura latina em língua portuguesa que são conhecidas na atualidade. ${ }^{8}$ Trata-se das traduções de quatro das Heroides de Ovídio e um epitáfio a Tibulo por João Rodriguez Lucena e João Rodriguez de Sá de Meneses. O Cancioneiro geral é dominado por apenas duas medidas, a redondilha maior (heptassílabo) e a menor (pentassílabo) e os dois tradutores escolheram o primeiro para a tradução dos dísticos elegíacos ovidianos. As redondilhas menores são usadas em gêneros de menor extensão e de estrutura fixa (esparsas, cantigas e vilancetes). A ligação desse metro com tais estruturas fixas (na forma de mote seguido de glosas), inadequadas para uma tradução por pressupor a criação de estrofes originais em diálogo com o mote de outro autor, pode ser evocada para explicar por que o verso foi preterido apesar de certa coincidência temática: o tema das esparsas é frequentemente o lamento amoroso, ao passo que o tema dos vilancetes e cantigas é o sofrimento causado por um amor não correspondido, muitas vezes em ambiente bucólico. Se tais aspectos explicariam a preterição da redondilha

\footnotetext{
${ }^{8}$ Ainda na Idade Média, aparece a obra Vida e feitos de Júlio César (MATEUS, 1970), traduzida a partir do francês Li fet des Romains por tradutor anônimo. A obra utiliza Salústio, Suetônio e Lucano como fontes e contém trechos da Farsália de Lucano traduzidos em prosa. Contudo, além de se tratar de tradução indireta, faz uso do poema apenas como fonte de informações sobre Júlio César e a história romana, sem interesse poético.
} 
menor, também não faltam razões para justificar a adoção da redondilha maior. Além de ser o verso mais longo, era também utilizado em contextos semelhantes aos usos dos versos antigos. No romanceiro popular, aparece ainda hoje como o metro de narrativas amorosas. No Cancioneiro geral, era o metro dos primeiros esboços de poesia histórica e heroica de temas por vezes relacionados às grandes navegações que se iniciavam (ROCHA, 1979, p. 51-54). Mais do que isso, alguns classicistas conjecturam a respeito da destinação das epístolas ovidianas a uma representação teatral na Roma antiga (NÉRAUDAU, 2003, p. 19-21) e a redondilha maior é o verso predominante nos primeiros esboços teatrais palacianos (REBELLO, 1977), como é possível perceber a partir dos entremezes compilados por Garcia de Resende, dos momos testemunhados e em parte transcritos pelos cronistas, e dos autos de Gil Vicente, que também figura entre os autores do Cancioneiro.

Percebe-se que as semelhanças até aqui evocadas são funcionais: o metro traduzido é o dístico elegíaco, constituído de um hexâmetro seguido por um pentâmetro, que os tradutores, no entanto, verteram indiferenciadamente por redondilhas maiores, apagando a particularidade formal de cada metro. Ora, conforme avalia Neves em seus estudos sobre a presença dessas traduções no Cancioneiro geral,

O porquê da escolha de determinadas cartas e não de todas também é relevante, já que se tratava do momento das navegações e, portanto, necessitava-se acalmar o coração das damas que permaneceram em terras lusitanas à espera de seus amados ausentes. E ainda, propor a elas um modelo de comportamento. (NEVES, 2013, p. 7)

Essa unificação métrica concorre para a interpretação de Neves, pois tem como consequência a integração de tais epístolas elegíacas de caráter simultaneamente amoroso e lamentoso ao cenário épico histórico. ${ }^{9}$

${ }^{9}$ Sobre o tema, veja-se Dias (1982). 
Tal integração logo será confirmada por Camões nos Lusíadas e, mais tarde, reafirmada por Fernando Pessoa em Mensagem. ${ }^{10}$

Acrescenta-se que as primeiras éclogas ${ }^{11}$ publicadas em língua portuguesa, as éclogas do também poeta palaciano Bernardim Ribeiro (c.1482-c.1552). ${ }^{12}$ são igualmente lavradas em redondilhas maiores e apresentam as mesmas características estróficas dessas traduções (décimas rimadas), porém com esquema de rimas levemente diferente (ababa-cdcdc em contraposição ao esquema abaab-cdccd das traduções das Heroides).

Nesse primeiro exemplo fica evidente o caráter flutuante das equivalências funcionais: se no período palaciano a redondilha maior tinha usos similares aos metros clássicos aqui estudados, a introdução do verso italiano por Sá de Miranda (1481-1558) em 1527 altera o equilíbrio do sistema e obriga a uma reorganização da hierarquia, realizando a ruptura que perdura até hoje: a correspondência funcional se perde, uma vez que a literatura, ou antes oratura, lavrada nesses versos tem

${ }^{10}$ Uma ilustração exemplar é o poema X de sua segunda parte, "Mar Português", que inicia pelo dístico: "Ó mar salgado, quanto do teu sal/São lágrimas de Portugal?". Certamente não por acaso, essa elegia é lavrada em dísticos de decassílabo seguido por octossílabo, numa aproximação formal ao dístico elegíaco latino em que o hexâmetro (verso épico greco-latino) é substituído pelo decassílabo (verso épico português) e o octossílabo, pouco frequente na tradição poética portuguesa, é sentido como uma variação catalética do decassílabo. Esse efeito é reforçado pelo fato de que os seis octossílabos do poema têm a sexta sílaba forte, sendo que quatro são a última sílaba de uma palavra oxítona e um tem essa sexta sílaba como a penúltima de uma palavra paroxítona, mas seguida de elisão. Indo além nas correspondências formais, cada dístico de Pessoa encerra um sentido completo do mesmo modo que, em geral, ocorria com os dísticos de Tibulo, Propércio e Ovídio. Acrescente-se ainda que a elegia de Pessoa, assim como aquelas heroides presentes no Cancioneiro geral, aproxima-se também das cantigas d'amigo trovadorescas, sendo comum entre esses textos o lamento feminino pelo amigo distante e a relação com o mar.

${ }^{11}$ Gênero greco-latino composto em hexâmetros.

${ }^{12}$ Pereira (2008, p. 42): "Não cabe aqui discutir o problema da prioridade de Sá de Miranda ou de Bernardim Ribeiro na introdução da écloga no nosso País, já definitivamente esclarecido por A. J. da Costa Pimpão, que considera Alejo a primeira bucólica à maneira italiana, feita cerca de 1536, e precedida pela Basto e pelas cinco do poeta da Menina e moça". 
caráter popular na atual economia literária luso-brasileira, ao passo que o hexâmetro combinado com temas heroicos tinha caráter elevado no sistema literário greco-latino antigo.

Contemporaneamente, as redondilhas maiores foram retomadas, na forma de quadras populares rimadas: A. A. Peterlini (In NOVAK; NERI, 2003) se vale daquela ruptura para dar um efeito de sentido popular às suas traduções de epigramas satíricos de Marcial. Já no séc. XVIII, a Marquesa de Alorna compusera epigramas nesse formato, tal como A um pregador famoso (ALORNA, 1941, 175), contudo, Peterlini não apresenta sua escolha tradutória como uma retomada direta dessa tradição. Mais provavelmente ele a retoma por via de uma filiação à tradição popular brasileira: a medida velha palaciana, trazida para o Brasil naquele período das primeiras grandes navegações, enraizouse na tradição popular, permanecendo até hoje, e o tradutor parece ter considerado a tradicional quadra rimada funcionalmente correspondente ao sabor cômico dos epigramas de Marcial.

Tal divisão, em que a medida velha corresponderia aos temas e gêneros menos elevados enquanto a medida nova corresponderia aos mais elevados, remonta aos primeiros anos do classicismo português. Camões (c.1524-1579/80), por exemplo:

Não seguiu a peugada de António Ferreira que deixava displicentemente o metro tradicional "ao povo", mas antes, como Sá de Miranda, usou a redondilha $[. .$.$] em composições de estilo semelhante$ a textos do Cancioneiro geral. [...] Mas, como é natural, a maioria das composições adotam a medida nova que o Renascimento pôs em voga e alguns dos sub-géneros líricos herdados da estética clássica: o soneto, o terceto, a oitava rima e a ode, a elegia, a écloga.

O uso destas formas vasadas em decassílabos arrasta quase sempre uma atitude séria face aos temas tratados [...] (MATOS, 1980, p. 43). 
Antônio Ferreira (1528-1569), tendo abandonado completamente a medida velha, compõe sua obra integralmente no metro e nas formas italianas e clássicas: é célebre sua recusatio na Carta X, aludida por Matos (1980) na citação transcrita acima: "Vejo vir claro lume de Toscana,/ Neste arço; a antiga Espanha deixo ao povo". Tal afastamento das coisas do povo ecoa as ideias de Dante Alighieri, que, no livro II do seu De vulgari eloquentia, compôs uma verdadeira arte poética humanista vernácula ao sistematizar os usos da escola poética toscana:

Perguntemo-nos antes de mais nada se todos aqueles que compõem versos em vernáculo devam servir-se de sua forma ilustre. [...] o vernáculo em questão espera por aqueles que excelem pelo intelecto e pela cultura, desprezando os demais [...] ninguém defenderia sua conveniência aos montanheses e seus argumentos rústicos. A língua mais elevada convirá às concepções mais elevadas. Mas as concepções mais elevadas não podem ser encontradas onde não haja cultura e intelecto, e portanto a melhor língua não convém senão àqueles dotados de intelecto e cultura. Desta forma, a melhor língua não convém a todos que compõem versos, pois a maioria escreve versos sem cultura e sem intelecto. [...] Quanto ao ponto onde se afirmava que a mistura das coisas superiores com as inferiores renda lucros, afirmamos que isto é verdade apenas enquanto cesse a possibilidade de distingui-las, como quando se fundem ouro e prata. Quando a distinção entre as partes permanece, a inferior diminui ainda mais em valor, como quando belas mulheres são acompanhadas por outras feias. ${ }^{13}$ (ALIGHIERI, 2011, p. 25)

Com efeito, o odi profanum vulgus é um dos tópicos horacianos mais presentes na obra de Antônio Ferreira e dos quinhentistas portugueses (PEREIRA, 2008, p. 31). Dante define ainda as características que devem seguir aqueles que pretendem compor poesia em vulgar ilustre,

${ }^{13}$ Todas as citações do tratado De vulgari eloquentia são feitas a partir da tradução de Tiago Trisoldi (ALIGHIERI, 2011). 
determinando que devem se limitar aos temas, formas, metro, vocabulário e construções sintáticas mais elevados, definindo, um por um, quais seriam estes. No que diz respeito ao metro, o poeta toscano preceitua:

nossos predecessores usaram em suas composições os mais diferentes versos, como de resto fazem também os contemporâneos. Contudo, não conhecemos ninguém que até hoje tenha em suas medidas ultrapassado o decassílabo ou descido aquém do dissílabo. [...] O decassílabo mostra-se o mais esplêndido entre todos estes versos, seja por sua extensão no tempo, seja por sua capacidade em acolher conceitos, construções e vocábulos. [...] Todos os grandes mestres [italianos] mostraram ter consciência disto, pois iniciaram suas canções ilustres neste verso. [...] Apesar deste do qual tratamos mostrar-se, como merece, o mais célebre entre todos os versos, revela-se ainda mais esplêndido e elevado em sua excelência quando atua numa espécie de união com o hexassílabo, desde que mantenha a prioridade sobre este. ${ }^{14}$ (ALIGHIERI, 2011, p. 33)

Praticamente toda a poesia portuguesa clássica foi lavrada em decassílabos. Camões e Sá de Miranda continuam a usar também a medida velha, porém, apenas nos gêneros tradicionais portugueses (como trovas, vilancetes e cantigas). Desde Sá de Miranda, passando por Camões, até Antônio Ferreira e os restantes poetas do cânone quinhentista, qualquer gênero imitado da antiguidade clássica é lavrado no metro italiano: odes, elegias, cartas, epigramas, éclogas, épica. O mesmo Dante, tendo determinado qual seria o verso excelente, o decassílabo, diz também que temas poderiam ser tratados nesse verso:

\footnotetext{
${ }^{14}$ A tradução de Tresoldi foi adaptada com substituição de "endecasillabo", "trisillabo" e "setenario" respectivamente por "decassílabo", dissílabo" e "hexassílabo", seus correspondentes na nomenclatura portuguesa: diferentemente de brasileiros e portugueses, os italianos consideram uma sílaba átona após a última sílaba tônica na contagem silábica dos versos.
} 
Devemos portanto identificar quais sejam estes argumentos "grandíssimos". Por primeiro, o âmbito do útil; neste, considerando com sagacidade qual seja a meta de todos os que buscam a utilidade, descobriremos este argumento nada mais ser que a sobrevivência. Por segundo, o âmbito do agradável; para este afirmamos que o objeto sumamente agradável é aquele mais precioso aos nossos apetites sensuais, ou seja o amor físico. Em terceiro, o âmbito do honesto; para este, ninguém duvida estarmos tratando da virtude. Portanto são estas as três, ou seja Salus, Venus e Virtus, que merecem ser tratadas nas formas mais excelentes, pelos argumentos a elas relacionados: o valor nas armas, o ardor no amor e o controle na própria vontade. (ALIGHIERI, 2011, p. 29)

Desse modo, é fácil compreender a unificação métrica no tratamento de temas amorosos, heroicos ou morais: o chancelamento dessa unidade métrica revelar-se-á um tropismo com força suficiente para determinar a indistinção entre hexâmetros e pentâmetros na tradução de elegias latinas até a segunda metade do século XX, quando, por fim, os tradutores começarão a experimentar formas de reproduzir a diferença métrica entre os dois versos antigos. No sistema português quinhentista, o que se torna distintivo de cada gênero são as estrofes utilizadas e tais estrofes, por sua vez, se diferenciam não pelos metros, mas pelo esquema de rimas. A épica, como é amplamente sabido, lavra-se em oitava rima (abababcc). A elegia é composta em terza rima ou tercetos encadeados (aba bcb cdc...). Talvez por aproximação das Heroides e Pônticas de Ovídio, as cartas são compostas na mesma estrofe das elegias. A écloga, gênero monométrico no mundo antigo, composto exclusivamente do mesmo hexâmetro dactílico do epos heroico, não recebe o mesmo tratamento do seu congênere elevado: na tradição portuguesa, é composta numa variedade de estrofes que inclui a oitava rima, a terza rima, longas estrofes rimadas, quadras rimadas e também alguns trechos em versos brancos. O epigrama, que na antiguidade caracterizava-se por poder ser 
lavrado numa variedade de metros, sendo o dístico elegíaco apenas um deles (Cf. CAIROLLI, 2015), entre os quinhentistas é lavrado numa única estrofe em oitava rima. Por fim, a ode, gênero lavrado em estrofes polimétricas na tradição antiga, tem esse efeito reproduzido por meio dos dois metros cuja combinação já era louvada por Dante, o decassílabo e o hexassílabo (ou decassílabo com pé quebrado) em estrofes sempre rimadas. A essa lista acrescenta-se a tragédia clássica, cujo único exemplar português, a Castro de Antônio Ferreira, tem a polimetria característica do gênero representada do mesmo modo que a polimetria das odes, porém com versos brancos. ${ }^{15}$

No que diz respeito aos dísticos (presentes nas elegias e cartas), há um aspecto em que há notável correspondência formal: não escapou aos quinhentistas o fato de que cada dístico nas elegias latinas de Tibulo, Propércio e Ovídio encerra um sentido completo, quase sempre terminando em pontuação forte: a cada dístico antigo corresponde um terceto português igualmente, encerrando um significado completo e terminado por pontuação forte. É também notável que há uma aproximada equivalência material: um dístico elegíaco pode variar entre 25 e 31 sílabas, já o terceto encadeado tem uma extensão que varia de 30 a 36 sílabas conforme seus versos sejam agudos, graves ou esdrúxulos.

${ }^{15}$ Camões ainda compõe o seu auto de tema clássico, o Auto dos Enfatriões, em redondilhas maiores como os autos de Gil Vicente e da escola vicentina. As comédias clássicas portuguesas, duas de Sá de Miranda, duas de Antônio Ferreira e três de Jorge Ferreira de Vasconcelos são todas escritas em prosa. No prólogo de sua primeira comédia, Os estrangeiros, Sá de Miranda deixa claro que está introduzindo um novo gênero, vindo da antiguidade, nas letras portuguesas: não poderia, portanto, manter o mesmo metro dos autos populares. Também não poderia, no entanto, usar o decassílabo, reservado aos temas mais elevados. Pode-se perguntar se a escolha da prosa por Sá de Miranda não teria reflexos ainda hoje no fato de as traduções de comédias clássicas em versos serem mais raras do que as traduções versificadas de tragédias. Com efeito, apenas temos notícia das recentes traduções em verso das comédias Lisistrata, Temosforiantes e As rãs de Aristófanes por Trajano Vieira (ARISTÓFANES, 2014a, 2014b) e de uma tradução em verso da comédia $O s$ adelfos de Terêncio por Rodrigo Tadeu Gonçalves, prevista para ser publicada pela editora Autêntica. 
No Renascimento português, a influência de Horácio foi maior do que a dos poetas elegíacos. ${ }^{16}$ Muitos já apontaram diversas imitações e, por vezes, traduções literais de Horácio entre os quinhentistas portugueses (cf. PEREIRA, 2008). Nas odes portuguesas, é frequente o uso de uma estrofe composta por três decassílabos seguidos por um hexassílabo, estrofe formalmente muito próxima da estrofe sáfica frequentemente usada por Horácio em suas odes. É, por exemplo, a estrofe da ode VI do livro I dos Poemas lusitanos, "uma tradução muito literal, que não omite quase nada" e em que "a correspondência com a ode III do livro I de Horácio é quase perfeita" (PEREIRA, 2008, p. 31-32). No século XVI, todavia, não encontramos nenhuma tradução de elegia clássica, seja na forma da elegia portuguesa, seja em outra estrofe. No sentido inverso, as elegias VII e VIII de Antônio Ferreira são traduções livres de textos gregos de tema amoroso, respectivamente $O$ Amor fugido de Mosco e $O$ Amor perdido, então atribuído a Anacreonte. O Amor fugido também foi traduzido por Pedro de Andrade Caminha, na sua elegia VIII. Nenhum desses textos, porém, é originalmente uma elegia: o Éros drapétes de Mosco é lavrado em hexâmetros (DINIZ, 2014, p. 27) e a Anacreontea XXXIII é lavrada em dímetro iônico anaclômeno (JESUS, 2009, p. 9): a escolha da forma das traduções ou paráfrases deve-se, provavelmente, à adequação da temática amorosa ao gênero elegíaco. Para ilustrar ainda essa liberdade na escolha do gênero da tradução, o epigrama XXV de Pero de Andrade Caminha é uma tradução da mesma Anacreontea XXXIII em uma única estrofe em oitava-rima, bastante diferente da estrofe elegíaca utilizada por Antônio Ferreira para traduzir o mesmo poema e que, portanto, não se destinava exclusivamente à tradução de poemas hexamétricos.

\footnotetext{
${ }^{16}$ Pereira (2008, p. 30): “O exemplo de veneração por Horácio foi dado por Petrarca no seu Ad Horatium Flaccum lyricum poetam (Epistolae de rebus familiaribus, XXIV, 10) e por Poliziano na ode que precede a edição florentina do Venusino (1482). Muitos dos nossos poetas quinhentistas imitaram ou traduziram Horácio, desde Camões ao quase esquecido André Falcão de Resende".
} 
No século XVIII, a elegia não será praticada com a mesma regularidade com que aparece nos poetas quinhentistas, ${ }^{17}$ porém, aparece com a mesma terza-rima nas obras da Marquesa de Alorna, de Bocage e de Manuel Inácio de Sousa. Durante este século, a par das criações elegíacas originais em terza rima, há as traduções de Ovídio Am. I, 1 e Tibulo, III, 4 por Filinto Elísio (1999, p. 390; 2001, p. 24), já em versos brancos contínuos, sem divisão em estrofes. Apenas nos anos finais deste século a terza rima será explorada como correspondência estrófica numa tradução de poemas em dísticos elegíacos, mais uma vez, as Heroides de Ovídio: em 1789, Miguel do Couto Guerreiro publica as Cartas de Ovídio, chamadas Heroides "traduzidas em rima vulgar". E é essa mesma estrofe, então considerada "rima vulgar", ou popular, que o poeta Antônio Feliciano de Castilho usará para traduzir a primeira dessas mesmas Heroides, a epístola de Penélope a Ulisses. ${ }^{18}$ Contemporaneamente, Vieira (2008) utiliza um terceto de decassílabos brancos para cada dístico elegíaco na sua tradução da elegia I, 9 dos Amores de Ovídio: embora deixando de lado a rima, mantém a estrofe de tercetos decassílabos com um sentido completo em cada terceto, quase sempre encerrado por pontuação forte. $\mathrm{O}$ tradutor parece, entretanto, não atentar para a relação já tradicional dessa estrofe com o gênero elegíaco em língua portuguesa:

A terceira estrofe de que me servi foi um terceto composto de decassílabos brancos através do qual traduzi o poema I, 9. Motivou a escolha dessa estrofe, uma necessidade formal bastante específica: ela facilitava uma equivalência ao verso ecóico que fecha o primeiro dístico. Ao fim do trabalho, no entanto, os tercetos em versos brancos também se revelaram um

\footnotetext{
${ }^{17}$ Filinto Elísio, por exemplo, embora tenha traduzido uma elegia de Ovídio e uma de Tibulo, não cultivou o gênero.

${ }^{18}$ Infelizmente, até onde pudemos averiguar, essas traduções de Castilho permanecem inéditas. Vansan (2016) transcreve e reproduz o fac-símile da carta I, de Penélope a Ulisses. José Feliciano de Castilho (1862, p. XXXV) ao listar as traduções de Ovídio feitas por seu irmão, inclui as Heroides: "Algumas param em nosso poder. Tenciona o poeta completá-las, com tal variedade de metrificação, que encubra a monotonia dos infelizes amores de tais personagens.
} 
fecundo equivalente ao dístico elegíaco (VIEIRA, 2008, p. 26).

Se os tercetos encadeados das elegias terão que esperar até os anos finais do séc. XVIII para ser explorados enquanto correspondência funcional na tradução de elegias greco-latinas, a oitava rima já no séc. XVII encontra notável emprego numa tradução integral da Eneida, poema hexamétrico de Virgílio. O tradutor, o camonista João Franco Barreto, chamou seu projeto de Eneida portuguesa (1664) mostrando já no título sua intenção de fazer uma Eneida acomodada ao sistema literário português de então. Com efeito, para além da estrofe, outros elementos aproximam esse texto à tradição épica lusitana ou, mais precisamente, camoniana: ${ }^{19}$

ler João Franco Barreto na sua versão da Eneida é ler Camões n'Os Lusíadas: não há oitava em que se não reconheça a presença camoniana, seja no vocabulário, seja na entonação, seja nos latinismos sintáticos, enfim, no espírito que de toda a versão se destila. (ALMEIDA, 1981, p. 19). ${ }^{20}$

Franco Barreto traduziu também a "Batrachomyomachia de Homero em 112 outavas portuguezas" (MACHADO; FARINHA, 1786, p. 290), tradução que permanece inédita até hoje. Em pleno período neoclássico, a oitava rima ainda aparece como estrofe da tradução da Ilíada pela Marquesa de Alorna (1750-1839). A poeta árcade traduziu os primeiros 516 versos do poema homérico em 123 estâncias de oitava rima (984 versos), nas quais elimina quase todos os epítetos, procedendo, assim, diferentemente de Franco Barreto que, como diz Almeida:

\footnotetext{
${ }^{19}$ Antônio Ferreira já utilizara a oitava rima no seu poema História de santa Comba dos Vales, operando a substituição das redondilhas maiores usadas pelos autores de poemas de tema histórico no Cancioneiro geral pela estrofe italiana, preparando o terreno para Camões, que em 1572 dá enfim a lume Os Lusíadas, sendo logo imitado por Gabriel Pereira de Castro, autor da Ulisseia ou Lisboa edificada (1636), e por Brás Garcia de Mascarenhas (1596-1656), autor do Viriato trágico, publicado postumamente em 1699. ${ }^{20}$ Trevizam (2007) estuda mais detidamente a influência de Camões na tradução de João Franco Barreto.
} 
nada deixa de traduzir; pelo contrário: por vezes, completa o verso, para melhor entendimento do leitor, nem que seja acrescentando toda uma frase, como naquele episódio de Celeno (III, 245 e seg.), onde traduz: "Mais fétido e letal do que o Aqueronte", quando no latim apenas se diz: infelix uates. (ALMEIDA, 1981, p. 19)

Esses complementos que Almeida (1981) vê com bons olhos devem-se em grande parte à necessidade de se completar a estrofe ou de criar as rimas. O próprio Almeida refere a crítica de Inocêncio Francisco da Silva, autor do Diccionario bibliographico portuguez (1859, p. 380), que considera a tradução de Franco Barreto "em demasia parafrástica" e lamenta "que muitas vezes não reproduza fielmente o sentido do original, em razão das dificuldades da rima, a que o tradutor quis sujeitar-se". Essa crítica à rima tem origem no século XVIII, conforme se lê no discurso preliminar de Cândido Lusitano à sua tradução da Arte poética de Horácio:

O hexâmetro, como não está ligado a uma certa uniformidade de terminações, nem se restringe à necessidade de cadências, não admite palavras ociosas, nem impede, que o Poeta possa variar a medida, o número, e a harmonia, segundo o pedir a ocasião. Ora esta vantagem não tem a Poesia vulgar, porque é uma escrava da rima, que nasceu nos séculos bárbaros, devendo sua origem aos versos rítmicos, e leoninos, que foram as fezes do metro Latino. ${ }^{21}$ (Lusitano, 2018, p. 54)

Se a crítica de Cândido Lusitano se refere ao fato de que as rimas estorvam a expressão do pensamento do poeta, tal crítica é tanto mais evidente quando se trata de uma tradução, uma vez que existe a possibilidade de cotejar os textos. Para breve ilustração, compare-se a primeira estrofe de Franco Barreto com os versos de Virgílio:

${ }^{21}$ Operamos a atualização ortográfica sem alterar, no entanto, a pontuação original. 
Arma uirumque cano, Troiae qui primus $\mathrm{ab}$ oris

Italiam fato profugus Lauinaque uenit litora - multum ille et terris iactatus et alto ui superum, saeuae memorem Iunonis ob iram, ${ }^{22}$
As armas e o varão eu canto, piedoso, Que primeiro de Tróia desterrado A Itália trouxe o Fado poderoso, E às praias de Lavino veio armado; Aquele que, no golfo tempestuoso E nas terras foi muito contrastado, Por violência dos Deuses e excessiva Lembrada ira de Juno vingativa. ${ }^{23}$

$\mathrm{Na}$ tradução desses quatro versos, seis palavras que não correspondem a nenhum termo do original são acrescentadas, todas na posição final dos versos, todas adjetivas, complementando os versos e criando as rimas. É libertando-se de dificuldades desse tipo e seguindo o lema árcade antibarroco, inutilia trunca, que Cândido Lusitano, a própria Marquesa de Alorna, Bocage, Almeno, Elpino Duriense, Filinto Elísio, José Agostinho de Macedo, José Anastácio da Cunha, enfim, os tradutores de literatura clássica no Portugal setecentista utilizarão os decassílabos brancos em suas traduções, assim como o farão na maior parte de suas criações originais.

\section{Considerações finais}

A observação dos metros empregados nos séculos XVI e XVII em Portugal para a tradução e imitação dos gêneros clássicos indica uma predominância da busca por correspondências funcionais, confirmando para este aspecto, tempo e lugar específicos o caráter culturalmente etnocêntrico que Berman (2012, p. 34) afirma ser predominante na tradução literária no Ocidente como um todo. Porém, neste caso, mais do que o etnocentrismo acusado pelo teórico francês, parece ser a intransponível diferença prosódica entre as línguas que explica tal postura, uma vez que na imitação e tradução de gêneros italianos, tal como o soneto, por esses mesmos poetas, observa-se não só uma

\footnotetext{
${ }^{22}$ Cito a partir da edição de Gian Biagio Conte (VERGILIVS MARO, 2009, p. 1).

${ }^{23}$ Cito da edição de Justino Mendes de Almeida (BARRETO, 1981, p. 31). Destacamos em itálico as palavras acrescentadas pelo tradutor.
} 
grande correspondência a nível temático, mas igualmente a nível formal (ANASTÁCIO, 1998, 2005), correspondência permitida pelo fato de que as duas línguas em questão têm uma prosódia acentual.

A observação desse período de transição permite que se opere uma despolarização desses conceitos, relativizando a oposição estanque e absoluta entre correspondência formal e correspondência funcional que, de fato, tendem a levar a resultados bastante diferentes. O contraste entre Bernardim Ribeiro e Sá de Miranda, respectivamente primeiro e segundo cultor da primitiva écloga portuguesa, nos ajuda a entrever a dinâmica da passagem da medida velha para a nova. Enquanto Bernardim Ribeiro ainda usava a medida velha mesmo para os novos gêneros clássicos (éclogas e cartas), Sá de Miranda já usa exclusivamente a medida nova para esses gêneros. Do mesmo modo, ao passo que a medida nova é completamente ausente do Cancioneiro geral, a influência de Dante e Petrarca já era sensível no tratamento dos temas amorosos que, em alguns casos, já não é o tratamento trovadoresco:

em proporção menor [quando comparadas a poesias ligadas à herança nacional], apontam também, aqui e acolá, sugestões ainda canhestramente aproveitadas duma vita nuova apenas vislumbrada, e que se traduz por laivos ocasionais de humanismo, de dantismo e de petrarquismo (ROCHA, 1979, p. 23).

Isso testemunha que após o contato inicial com a poética italiana a adoção dos temas e do modo de abordá-los precedeu a adoção do metro estrangeiro, que causava maior estranhamento e, consequentemente, maior dificuldade de aceitação, como testemunha a carta em decassílabos que Sá de Miranda dirigiu a Antônio Ferreira sobre o momento de transição nas letras portuguesas:

uma pergunta escura, esparsa triste!

Tudo bom! Quem o nega? Mas porque, se alguém descobre mais, se lhe resiste?

(MIRANDA, 1989, p. 462) 
Tal dinâmica também é significativa para a compreensão da relação entre imitação e tradução. Os latinismos sintáticos de João Franco Barreto, por exemplo, eram chancelados não pelo original de Virgílio, mas pela prática de Camões, que os tinha utilizado não numa tradução, mas num poema original, o que lhe resguardara de acusações de servilidade ou ingênua literalidade ${ }^{24}$. Essa mesma preocupação tem lugar também no século XVIII, nas constantes justificativas que tradutores como Bocage e, sobretudo, Filinto Elísio dão para latinismos sintáticos ou lexicais em suas traduções: esses poetas-tradutores setecentistas evocam quase sempre usos dos clássicos portugueses quinhentistas para chancelar os seus próprios usos e defender-se das críticas ${ }^{25}$.

É difícil não perceber aqui um paralelismo com uma transição muito anterior na longa história do hexâmetro. Flores (2011, p. 141) oportunamente recorda que a literatura latina é fundada por uma tradução da Odisseia na qual Lívio Andrônico recorreu a um verso latino, o saturnino, para traduzir o hexâmetro homérico. Dando prosseguimento ao raciocínio, ganha destaque o papel exercido por Ênio nas letras latinas: em lugar de seguir a tradição de utilizar os saturninos para compor sua narrativa épica, encontrou um correspondente formal para o hexâmetro grego, possivelmente sendo o criador do hexâmetro latino e enriquecendo a literatura latina com elementos lexicais e formais helenísticos que foram absorvidos e apropriados pela tradição (cf. CARDOSO, 2013, p. 9). Entre Lívio Andronico e Ênio, poetas como Névio imitaram, cantando os temas

\footnotetext{
${ }^{24}$ Camões imita a estrofe da epopeia italiana de Ariosto, com a importante diferença de que o poeta português passa ao largo da matéria francesa escolhida pelo poeta italiano e compõe a epopeia do povo luso, diretamente relacionada ao momento de preeminência histórica que Portugal vivia então e que, conforme visto anteriormente, já havia surgido, como tema de poesia histórica nacional no Cancioneiro geral. Também vale lembrar que a "arte poética" humanista de Dante dedica um capítulo exclusivamente à construção sintática (constructio), o capítulo VI do livro II, no qual já preceitua que os poetas busquem uma sintaxe elevada na imitação dos antigos, nomeadamente os épicos Virgílio, Ovídio, Estácio, Lucano e, na prosa, Tito Lívio, Plínio e Frontino (ALIGHIERI, 2011, p. 35).

${ }^{25}$ Veja-se, por exemplo, as notas de Filinto Elísio à sua tradução da Punica de Sílio Itálico (ELÍSIO, 1998).
} 
históricos nacionais, o gênero épico introduzido por Andronico. Nos Anais de Ênio, o metro estrangeiro estará a serviço da elevação de um tema eminentemente nacional e até o surgimento da Eneida, esses Anais serão o grande épico nacional latino. Finalmente, quando Cícero traduz os versos 226-229 do canto XIX da Ilíada (Tusculanae disputationes III, 65,12 ) utilizando o hexâmetro, ao contrário de Ênio, já está utilizando um verso latino.

Num contexto de estabelecimento das línguas e identidades nacionais, a imitação é o mecanismo de apropriação que torna nacional o estrangeiro e, no que diz respeito à tradução, transforma em correspondência funcional o que originalmente seria uma correspondência formal. Essa dinâmica parece ser fundamental na absorção da influência estrangeira, amortecendo seu impacto e evitando um duplo abandono da identidade nacional. Ou seja, é possível pensar, embora hipoteticamente, que há uma maior resistência a traduções formalmente correspondentes à obra estrangeira, uma vez que isso representaria o simultâneo abandono da cultura local, tanto pelo viés da matéria quanto pelo viés da forma, distanciando em demasia leitor e texto.

Esse mecanismo de gradual aclimatação é parte do que explica a adoção tardia da terza rima como correspondente funcional na tradução de elegias. No que diz respeito especificamente ao metro, ao completar esse percurso de apropriação, facilitado pela proximidade entre as línguas italiana e portuguesa, o decassílabo se estabelece como metro nobre da poesia em língua portuguesa e se torna o verso de referência para o que poderíamos chamar de "lusitanidade poética" (ou seja, referência para quem busca inserir sua tradução poética no sistema literário português sem que ela seja sentida como elemento estranho) e exclui qualquer metro mais extenso como barbarismo. Ao longo dos séculos seguintes, observa-se a lenta introdução de versos mais longos no sistema métrico português, a começar pelos alexandrinos franceses. Como recorda Britto (2006, p. 56), é por meio das correspondências formais que a tradução se revela um frutífero meio de enriquecer a língua de novas formas. Gêneros tão tradicionais em língua portuguesa como o soneto e a oitava-rima (junto a seu metro decassílabo) um dia tiveram de ser importados dos 
italianos, ou seja, foram elementos estranhos ao sistema e cuja introdução precisou ser defendida por seus cultores antes de serem absorvidos. O apelo implícito na carta de Sá de Miranda a Antônio Ferreira merece ser relembrado antes de criticarmos por artificialidade experimentos como a introdução do verso de 14 sílabas ou do verso núnico de 16 sílabas, além das tentativas mais recentes de criação de correspondentes formais dos metros greco-latinos em português.

\section{Referências}

ALIGHIERI, D. De Vulgari Eloquentia. Sobre a eloquência em vernáculo. ed. bilíngue. Tradução, introdução e notas de Tiago Tresoldi. Porto Alegre: Tiago Tresoldi Editore, 2011.

ALMEIDA, J. M. de. Introdução. In: BARRETO, J. F. Eneida Portuguesa. Com introdução, notas, actualização e estabelecimento do texto por Justino Mendes de Almeida. Lisboa: Imprensa Nacional-Casa da Moeda, 1981.

ALORNA, L. de A. Poesias. Selecção, prefácio e notas de Hernani Cidade. Lisboa: Sá da Costa, 1941.

ANASTÁCIO, V. Pensar o petrarquismo. Revista Portuguesa de História do Livro, Lisboa, ano VIII, n. 16, p. 41-80, 2005.

ANASTÁCIO, V. Visões de Glória (Uma introdução à poesia de Pêro de Andrade Caminha).. Lisboa: Fundação Calouste Goulbenkian, 1998. v. I ARISTÓFANES. As rãs. Tradução de Trajano Vieira. São Paulo: Cosac \& Naify, 2014a.

ARISTÓFANES. Lisistrata e Tesmoforiantes. Tradução de Trajano Vieira. São Paulo: Perspectiva, 2014b.

BARRETO, J. F. Eneida Portuguesa. Com introdução, notas, actualização e estabelecimento do texto por Justino Mendes de Almeida. Lisboa: Imprensa Nacional-Casa da Moeda, 1981.

BERMAN, A. A tradução e a Letra ou o Albergue do Longínquo. Tradução de Marie-Hélène C. Torres, Mauri Furlan e Andreia Guerini. 2. ed. Santa Catarina: PGET-UFSC, 2012. 
BRITTO, P. H. Correspondência formal e funcional em tradução poética. In: SOUZA, Marcelo, P. et alii (org.). Sob o signo de Babel: literatura e poéticas da tradução. Vitória: Flor\&Cultura, 2006.

CAIROLLI, F. P. Os epigramas de Marcial e seus ritmos em português. Cadernos de Literatura em Tradução, São Paulo, n. 15, p. 123-137, 2015.

CARDOSO, Z. de A. A literatura latina. São Paulo: Martins Fontes, 2013.

CASTILHO, J.F. de. Prefação. In: OVÍDIO. Arte de amar. Tradução de Antônio Feliciano de Castilho. Rio de Janeiro: Eduardo \& Henrique Laemmert, 1862.

COHEN, R. From Folksong to Lyric Theater: The Evolution of the Cantigas d'Amigo. In: CALDERON, M. (org.). Por s'Entender Bem a Letra. Homenagem a Stephen Reckert. Lisboa: Imprensa Nacional-Casa da Moeda, 2011. p. 637-663.

DIAS. A. F. Sentimento heróico e poesia elegíaca no Cancioneiro Geral. Biblos, Coimbra, v. LVIII, p. 268-299, 1982.

DINIZ, F. G. M. A tradução à luz da tradição: as traduções neoclássicas do poema Éros Drapétēs, de Mosco, e o espaço para novas propostas de tradução. Rónai - Revista de Estudos Clássicos e Tradutórios, Juiz de Fora, v. 2, p. 25-41, 2014.

DUARTE, A. da S. Por uma história da tradução dos clássicos grecolatinos no Brasil. Translatio, Porto Alegre, n. 12, p. 43-62, 2016.

ELÍSIO, F. Obras completas. Edição de Fernando Moreira. Braga: APPACDM, 1998. v. II.

ELÍSIO, F. Obras completas. Edição de Fernando Moreira. Braga: APPACDM, 1999. v. V.

ELÍSIO, F. Obras completas. Edição de Fernando Moreira. Braga: APPACDM, 2001. v. XI.

FERNANDES, T. A literatura latina no Brasil: uma história de traduções. 2017. 205 f. Tese (Doutorado em Estudos da Tradução) - Universidade Federal de Santa Catarina, Florianópolis, 2017.

FLORES, G. G. Traduzibilidades em Tibulo 3.20. Scientia Traductionis, São Paulo, n.10, p. 141-150, 2011. Doi: https://doi.org/10.5007/19804237.2011n10p141 
GONÇALVES, R. T. et alii. Uma tradução coletiva das Metamorfoses 10. 1-297 com versos hexamétricos de Carlos Alberto Nunes. Scientia Traductionis, São Paulo, n. 10, p. 110-132, 2011. Doi: https://doi. org/10.5007/1980-4237.2011n10p110

HOMERO. Ilíada. Texto integral (em verso). Tradução de Manuel Odorico Mendes. São Paulo: Martin Claret, 2003.

HOMERO. Ilíada. Tradução de Frederico Lourenço. Lisboa: Cotovia, 2014a.

HOMERO. Ilíada. Tradução de Odorico Mendes. Organização, prefácio e notas de Sálvio Nienkötter. Cotia: Ateliê Editorial; Campinas: Editora Unicamp, 2010.

HOMERO. Odisseia. Texto integral. Tradução de Odorico Mendes. São Paulo: Martin Claret, 2002.

HOMERO. Odisseia. Tradução de Frederico Lourenço. Lisboa: Cotovia, 2014b.

HOMERO. Odisseia. Tradução de Odorico Mendes. Organização de Antônio Medina. São Paulo: Edusp, 2000.

HORÁCIO. Arte Poética. Traduzida em verso e comentada por Cândido Lusitano. Porto Alegre: Concreta, 2017?.

JESUS, C. A. M de. Anacreontea. Poemas à maneira de Anacreonte. Edição bilíngue Grego-Português. Tradução, estudo introdutório e notas de Carlos Alberto Martins de Jesus. Coimbra: Fluir Perene, 2009.

LUCANO. Farsália. Cantos de I a V. Introdução tradução e notas de Brunno V. G. Vieira. Campinas: Unicamp, 2011.

LUCRÉCIO. Da natureza das coisas. Tradução de Luís Manuel Gaspar Cerqueira. Lisboa: Relógio d'água, 2015.

LUSITANO, C. Discurso preliminar do traductor. In: HORÁCIO FLACCO. Arte poética. Traduzida, e illustrada em Portuguez por Cândido Lusitano. Reedição de Ângela Correia, Érica Carvalho, Melanie Madeira e Mónica Rosendo. Lisboa: Bibliotrônica Portuguesa, 2018. p. 19-63. 
MACHADO, D. B.; FARINHA, B. J. de S. Summario da Bibliotheca Lusitana. Tomo II. Lisboa: Officina de Antonio Gomes, 1786. Disponível em: https://books.google.com.br/books?id=W5YDAAAAQAAJ\&pg=P A290\&lpg=PA290\&dq=joao+franco + barreto + batrachomyomachia + de + homero\&source $=$ bl\&ots $=$ mUMS8vPXcv\&sig $=$ uPR1csZS_S1WAu40SQiXHx7RHA\&hl=pt-BR\&sa=X\&ved=2ahUKEwia_5G480DdAhUBF ZAKHZnPD2IQ6AEwBHoECAUQAQ\# $\mathrm{v}=$ onepage $\& \mathrm{q} \& \mathrm{f}=$ false. Acesso em: 29 set. 2018.

MATEUS, M. H. M. Vida e feitos de Júlio César. Edição crítica da tradução portuguesa quatrocentista de "Li fet des Romain" por Maria Helena Mira Mateus. Lisboa: Fundação Calouste Gulbenkian, 1970.

MIRANDA, F. de S. de. Poesias. Edição de Carolina Michaelis de Vasconcelos. 2. ed. Lisboa: Imprensa Nacional-Casa da Moeda, 1989.

NÉRAUDAU, J.-P. Prefácio. In: OVÍDIO. Cartas de amor: as Heroides. Tradução de Dunia Marinho Silva. São Paulo: Landy, 2003. p. 9-40.

NEVES, A. C. C. G. Presença das Heroides de Ovídio no Cancioneiro Geral de Garcia de Resende. 2013. 292f. Dissertação (Mestrado) Faculdade de Filosofia, Letras e Ciências Humanas, Universidade de São Paulo, 2013.

NOVAK, M. da G.; NERI, M. L. (org.). Poesia lírica latina. São Paulo: Martins Fontes, 2003.

OLIVA NETO, J. A. 11 poemas de Propércio (I, 1-11) traduzidos com o verdadeiro dístico elegíaco de Péricles Eugênio da Silva Ramos. Cadernos de Literatura em Tradução, São Paulo, n. 15, p. 151-183, $2016 \mathrm{a}$.

OLIVANETO, J. A. Sulpícia e as elegias amorosas de uma jovem romana. Organon, Porto Alegre, v. 31, n. 60, p. 267-278, 2016b. Doi: https://doi. org/10.22456/2238-8915.60783.

OVÍDIO. Amores \& Arte de Amar. Tradução, introduções e notas de Carlos Ascenso André; Prefácio e apêndices de Peter Green. São Paulo: Penguin-Companhia, 2011.

OVÍDIO. Amores. Tradução de Carlos Ascenso André. Lisboa: Livros Cotovia, 2006. 
OVÍDIO. Arte de amar. Tradução de Carlos Ascenso André. Lisboa: Livros Cotovia, 2008.

OVÍDIO. As metamorfoses. Organização de Mauri Furlan e Zilma Gesser Nunes. Florianópolis, UFSC, $2017 \mathrm{a}$.

OVÍDIO. Cartas de Ovídio, chamadas Heroides. Expurgadas de toda obscenidade e traduzidas e rima vulgar por Miguel do Couto Guerreiro. Lisboa: Officina de Francisco Luiz Ameno, 1789.

OVÍDIO. Heróides. Tradução de Carlos Ascenso André. Lisboa: Livros Cotovia, 2015.

OVÍDIO. Metamorfoses. Excertos traduzidos por Bocage. São Paulo: Martin Claret, 2003.

OVÍDIO. Metamorfoses. Seleta bilíngue traduzida por Bocage. Com comentários e glossário. Porto Alegre: Concreta, 2016.

OVÍDIO. Metamorfoses. Tradução de Domingos Lucas Dias. São Paulo: Ed. 34, $2017 b$.

OVÍDIO. Metamorfoses. Tradução de Manuel Maria Barbosa du Bocage. São Paulo: Hedra, 2000.

OVÍDIO. Metamorfoses. Tradução de Manuel Maria Barbosa du Bocage. Edição de Bolso. São Paulo: Hedra, 2007.

OVÍDIO. Metamorfoses. Tradução de Paulo Farmhouse Alberto. Lisboa: Livros Cotovia, 2014.

OVÍDIO. Remédios contra o amor. Tradução de Carlos Ascenso André. Lisboa: Livros Cotovia, 2015.

PEREIRA, M. H. da R. Alguns aspectos do classicismo de António Ferreira. In:__. Temas clássicos na poesia portuguesa. 2. ed. Lisboa: Editorial Verbo, 2008.

RAMOS, P. E. da S. Poesia grega e latina, seleção notas e tradução direta do grego e do latim por Péricles Eugênio da Silva Ramos. São Paulo: Cultrix, 1964.

REBELLO, L. F. O primitivo teatro português. Lisboa: Instituto de Cultura Portuguesa, 1977. 
ROCHA, A. C. Garcia de Resende e o Cancioneiro Geral. Lisboa: Instituto de Cultura Portuguesa, 1979.

SOUZA, L. dos S. Bi-tradução do livro primeiro dos Amores de Ovídio: reflexões sobre dois modos de verter o dístico elegíaco. 2016. 211f. Dissertação (Mestrado) - Programa de Pós-Graduação em Letras da Universidade Federal do Paraná, Curitiba, 2016.

THAMOS, M. As armas e o varão: leitura e tradução do canto I da Eneida. São Paulo: Edusp, 2011.

TIBULO. Poemas: cantos de amores. Tradução de Carlos Ascenso André. Lisboa: Livros Cotovia, 2015.

TREVIZAM, M. A Eneida Portuguesa de João Franco Barreto: tributária de Camões e Virgílio. Phaos, Campinas, n. 7, p. 123-138, 2007.

VANSAN, J. Poética e retórica nas Heroides de Ovídio: uma análise da Epístola I "De Penélope a Ulisses". 2016, 169f. Dissertação (Mestrado) - Programa de Pós-Graduação da Faculdade de Ciências e Letras da Universidade Estadual Paulista, São Paulo, 2016.

VERGILIVS MARO, P. Aeneis. Recensuit atque apparatu critico instruxit Gian Biagio Conte. Bibliotheca Teubneriana. Berlim; Nova Iorque: De Gruyter, 2009.

VIEIRA, B. V. G. O dístico elegíaco em português: tradução de Ovídio, Amores, I, 1, 4, 5, 9. Revista Eletrônica Antiguidade Clássica, Rio de Janeiro, n. 2, sem. II, p. 26-37, 2008.

VIRGÍLIO. Bucólicas. Tradução e comentário de Raimundo Carvalho. Belo Horizonte: Crisálida, 2005a.

VIRGÍLIO. Bucólicas. Tradução e notas de Odorico Mendes. Edição anotada e comentada pelo Grupo de Trabalho Odorico Mendes. Cotia: Ateliê Editorial; Campinas: Ed. Unicamp, 2008a.

VIRGÍLIO. Eneida Brasileira. Ou tradução poética da epopeia de Públio Virgílio Maro por Manuel Odorico Mendes da cidade de S. Luís no Maranhão. Campinas: Ed. Unicamp, 2008b.

VIRGÍliO. Eneida. Texto Integral. Tradução de Manuel Odorico Mendes. São Paulo: Martin Claret, 2004. 
VIRGÍLIO. Eneida. Tradução de Barreto Feio. Introdução de Paulo Sérgio Vasconcellos. São Paulo: Martins Fontes, 2004.

VIRGÍLIO. Eneida. Tradução de Luís M. G. Cerqueira, Cristina Abranches Guerreiro e Ana Alexandra T. L. Alves (Professores da Faculdade de Letras de Lisboa). Lisboa: Bertrand Editora, 2011.

VIRGÍLIO. Eneida. Tradução e notas de Odorico Mendes. Cotia: Ateliê Editorial; Campinas: Ed. Unicamp, 2005b.

Recebido em: 4 de outubro de 2018. Aprovado em: 29 de março de 2019. 